\title{
Mechano-growth Factor Expression in Colorectal Cancer Investigated With Fluorescent Gold Nanoparticles
}

\author{
SWETHAN ALAGARATNAM ${ }^{1}$, SHI-YU YANG ${ }^{1}$, MARILENA LOIZIDOU ${ }^{1}$, \\ BARRY FULLER $^{2}$ and BALA RAMESH ${ }^{1}$ \\ ${ }^{1}$ University College London Centre for Nanotechnology and Regenerative Medicine, \\ Division of Surgery and Interventional Science, University College London, Royal Free Campus, London, U.K.; \\ ${ }^{2}$ University Department of Surgery and Liver Transplant Unit, \\ University College London, Royal Free Campus, London, U.K.
}

\begin{abstract}
Background/aim: Fluorescent gold nanoparticles demonstrate strong photoluminescence, photostability, and low cellular toxicity, making them attractive agents for biomedical applications. Mechano-growth factor (MGF) is an isoform of IGF 1 and its expression has been demonstrated in malignancies including prostate cancer. Materials and Methods: Nearinfrared-emitting gold nanoparticles (AuNPs) were synthesized and conjugated to MGF. Following characterization and confirmation of conjugation, these AuNPs were used to investigate the expression of MGF in colon cancer cell lines (HT29 and SW620) and tissues comparing normal and colon cancer. The prostate cancer cell line PC 3 and adenocarcinoma tissues were used as positive controls. Results: Colon cancer cell lines, adenocarcinoma tissues and polyp tissues demonstrated evidence of MGF peptide expression, which was not found in normal colon tissues and human umbilical vein endothelial cells. Conclusion: MGF appears to be overexpressed in colon cancer tissues, offering a potential unique target for imaging and drug delivery in colon cancer.
\end{abstract}

Colorectal cancer is the third most commonly diagnosed cancer in males, and the second in females worldwide with an estimated 1.096 million new cancer cases and 551,269 deaths in 2018 (1). The overall 10-year survival rates for patients with colorectal cancer, estimated by Cancer Research UK, was $58.7 \%$ in the United Kingdom in the

This article is freely accessible online.

Correspondence to: Swethan Alagaratnam, University College London Centre for Nanotechnology and Regenerative Medicine, Division of Surgery and Interventional Science, University College London, 9th Floor, Royal Free Campus, London NW3 2QG, U.K. E-mail: swethan@doctors.org.uk

Key Words: Mechano-growth factor, gold nanoparticles, colon cancer, fluorescent nanoparticles.
2010-11 (2). Early diagnosis, as common to most malignancies, offers the best chance of long-term cure. Research into improving outcomes in colorectal cancer include better screening tests for early diagnosis and improving the efficacy of chemotherapy agents. This includes identifying proteins overexpressed by colorectal cancer cells which are not expressed by normal tissues, which would offer avenues for targeted drug delivery.

Mechano-growth factor is an isoform of insulin-like growth factor-1 (IGF1) which is generated from the splicing of exons 4,5 and 6 of the IGF 1 gene (3). It was initially demonstrated to be up-regulated in skeletal muscle after exercise and injury, and has subsequently been identified to have other physiological roles in neuroprotection in the setting of brain ischaemia, promoting cartilage regeneration at sites of damaged cartilage, and protection of cardiac tissues in ischaemia (4-7). Its role in cancer pathogenesis was recently investigated and initially confirmed in prostate cancer by work performed by the Department of Experimental Physiology at the University of Athens confirming that prostatic adenocarcinoma tissues demonstrate higher expression of MGF compared to normal prostate tissues and intra-epithelial neoplasia (8). Other malignancies identified to be likely overexpressing MGF include osteosarcomas and neuroendocrine tumours (9-11).

Fluorescent gold nanoparticles (AuNPs) demonstrate strong photoluminescence, photostability and good biocompatibility at nanometer dimensions (12). Such nanoparticles have been demonstrated to exhibit stronger emission intensity and photostability compared to fluorescent dyes, and do not have the inherent cytotoxicity of semi-conductor quantum dots (12, 13). These features make AuNPs an attractive option as diagnostic agents and potentially therapeutic roles through thernostatics $(14,15)$.

We describe the synthesis of gold quantum dots along with their functionalization and conjugation with MGF antibody. Using this antibody, we investigated the expression of the MGF peptide in colon cancer using cell lines and tissues. 


\section{Materials and Methods}

Reagents. All chemicals were of analytical grade. Mercaptosuccinic acid (MSA), gold (III) chloride trihydrate $\left(\mathrm{HAuCl}_{4} \bullet 3 \mathrm{H}_{2} \mathrm{O}\right)$, dimethyl formamide (DMF), N-(3-dimethylaminopropyl)-Nethylcarbodiimide hydrochloride (EDC) were purchased from Sigma-Aldrich (Sigma-Aldrich Company Ltd, Poole, Dorset, UK). In all preparations, high purity deionised water from a Millipore system was used.

Synthesis of MSA-stabilized AuNPs. The method used in this study involved a one-pot method to obtain visible fluorescent AuNPs as previously described (16). The precursor solution was prepared with a mixture of MSA $(50 \mathrm{mM})$ and $\mathrm{HAuCl} 4(25 \mathrm{mM})$ in $50 \mathrm{ml}$ of deionised water. After vigorous stirring of the precursor mixture for $5 \mathrm{~min}$, using a homogenizer at maximum speed, $500 \mu \mathrm{l}(12.9 \mathrm{M})$ dimethyl foramamide $(73.09 \mathrm{~g} / \mathrm{mol})$ was added to the mixing precursor solution for another $5 \mathrm{~min}$ at room temperature. This mixture was processed by hydrothermal treatment (autoclave) at $121^{\circ} \mathrm{C}$ for 25 min to produce quantum confined MSA-AuNPs with near-infrared emission at $800 \mathrm{~nm}$ on cooling to room temperature. The final product excited at a range from $375 \mathrm{~nm}$ to $630 \mathrm{~nm}$ produced a fluorescent peak at $800 \mathrm{~nm}$.

Gold nanoparticle characterization. The fluorescence spectra of the AuNPs and its conjugations were recorded to ensure that the emission fluorescence was not quenched in order to use them for different biomedical applications. Fluorescence spectra were taken by a spectrofluorometer with an excitation source at $488 \mathrm{~nm}$.

Transmission electron microscopy (TEM) (Phillips CM 120; Phillips, London, UK) was used for visualisation and to determine the size of AuNPs. To determine the size and shape of the coated AuNPs, a set of 1:100 serial dilutions were made of coated QDs with PBS and the optimum dilution was chosen. A drop of the samples was mounted on to a Piloform (TAAB) coated G300HS copper electron microscopy grid (Gilder Grids Ltd, Grantham, Lincolnshire, UK) and allowed to air dry. The grids were examined with by TEM at $3.0 \times 10^{5}$ magnification (data not shown).

Preparation of antibody to MGF conjugated to AuNP/MSA (anti$M G F-A u N P s)$. Fluorescent MSA-AuNP solution was diluted with equal volume of cold ethanol and centrifuged at $10,000 \times g$ for 30 minutes. The precipitated MSA-AuNPs were vacuum-dried to obtain a powder. The precipitated dried MSA-AuNPs (approximately $1 \mathrm{mg}$ ) were re-suspended in $1 \mathrm{ml}$ PBS. MSAAuNP solution $(1 \mathrm{ml})$ was conjugated to the anti-MGF (Merck Millipore, Burlington, MA, USA) using EDC as an acylating agent. Briefly, $200 \mu \mathrm{l}$ MSA-AuNP solution $(1 \mathrm{mg} / \mathrm{ml})$ was mixed with $200 \mu \mathrm{EDC}(1 \mathrm{mg} / \mathrm{ml})$ in water for 30 minutes at room temperature. Anti-MGF solution $(100 \mu \mathrm{lof} 5 \mathrm{mg} / \mathrm{ml})$ in PBS was added to the activated mixture and agitated gently for 1 hour at room temperature. To separate the reagent and unconjugated MSA-AuNPs, membrane centrifugal columns (Centricon, Thermo Fisher Scientific, Waltham, MA, USA) were used with a cut offof $100 \mathrm{kDa}$ with UV monitoring at $280 \mathrm{~nm}$ of the retained samples. Further validation of conjugation of the anti-MGF-AuNP was carried out using immunochemistry against the synthetic peptide via immunodots. The purified bio-conjugated nanoparticles defined as anti-MGF-AuNPs were collected and stored at $4^{\circ} \mathrm{C}$ until further use.
Dot-blot confirmation of anti-MGF conjugation to AuNPs. Dot-blot confirmation of functioning MGF antibody bound to AuNPs was performed as follows. Five microlitres of a 1:1,000 dilution of the synthetic MGF peptide $(1 \mathrm{mg} / \mathrm{ml})$ in PBS were spotted separately at three serial dilutions onto aqueous equilibrated polyvinylidene difluoride membrane (Hybond P; Amersham Pharmacia Biotech, Bucks, UK) and allowed to dry at room temperature along with a scrambled peptide sequence as a control. On drying, the membrane was rinsed briefly in PBS with $0.05 \%$ Tween 20 (PBS/T; pH 7.4) and was incubated overnight at room temperature in $2 \%$ bovine serum albumin with $0.005 \%$ sodium azide to block any residual binding sites on the membrane. After blocking incubation, the membrane strip was rinsed in PBS/T ( $5 \times 1$-minute washes). The second incubation was carried out in the presence of the anti-MGF conjugated to AuNPs at 1:1,000 for 1 $\mathrm{h}$ at room temperature with gentle shaking. The membrane strip was rinsed in PBS/T (5×1-minute washes). The third incubation was with anti-rabbit antibodies conjugated to horse radish peroxidase (Amersham ECL Rabbit IgG, HRP-linked whole donkey Ab, from GE Healthcare Life Sciences, GE Healthcare UK Limited, Amersham Place, Buckinghamshire, UK) (anti-rabbit-IgG, 1:5000) for 1 hour with gentle shaking. This third incubation was to confirm conjugation (anti-MGFAuNPs) and simultaneously the specificity to the peptide antigen (MGF). The strip was finally washed in PBS/T $(5 \times 5$-minute washes). The membrane was then used for chemiluminescence to detect the presence of the conjugated anti-MGF-AuNPs.

Cells. The cell lines were purchased from the European Collection of Cell Cultures (ECACC, Sigma-Aldrich Company Ltd, Poole, Dorset, UK). All cell cultures were routinely propagated in standard growth conditions $\left(37^{\circ} \mathrm{C}, 5 \% \mathrm{CO}_{2}\right)$. Cancer cell lines SW 620 (colon cancer), HT-29 (colon cancer) and PC3 (prostate cancer) were all maintained in Dulbecco's modified Eagle's medium (with $1 \mathrm{mM}$ pyruvate, $2 \mathrm{mM}$ glutamine and $10 \mathrm{mM}$ HEPES) supplemented with $10 \%$ foetal bovine serum (FBS), $100 \mathrm{IU}$ penicillin and $100 \mathrm{mg} / \mathrm{ml}$ streptomycin. Human umbilical vein endothelial cells (HUVECs; Sigma-Aldrich Company Ltd.) were maintained in Prom ${ }^{\circ} \mathrm{Cell}$ endothelial cell growth medium with supplement mix (Prom ${ }^{\circ} \mathrm{Cell}$ $\mathrm{GmbH}$, Germany) and 5\% FBS with growth factors.

After 24 hours of incubation at $37^{\circ} \mathrm{C}$ in $5 \% \mathrm{CO}_{2}$, the cells were washed with PBS and fixed with $4 \%$ paraformaldehyde solution for 1 hour at room temperature. These were then washed three times with PBS and incubated with anti-MGF AuNPs in PBS with $0.6 \%$ bovine serum albumin for 1 hour and then washed three times with PBS. Negative control was performed by using unconjugated AuQDs in exchange for anti-MGF-AuNPs.

Tissues. Frozen sections of colorectal cancer tissues, normal colon tissues and prostate cancer tissues fixed in cold acetone were purchased from AMS Biotechnology (Europe) Ltd. (Milton, Abingdon, UK). Prostate cancer tissues were chosen as positive controls due to established findings in the literature for the overexpression of MGF in prostate cancer compared to normal prostate tissues (17). These tissues were incubated with the antiMGF-AuNPs in PBS with $0.6 \%$ bovine serum albumin for 1 hour and then washed three times with PBS. Negative control was performed by using unconjugated AuNPs in exchange for the anti-MGF-AuNPs.

Laser scanning confocal fluorescent microscopy. Images of the cells and tissues were acquired by fluorescent microscopy (Olympus BX 63; KeyMed House, Southend-on-Sea, UK) which can operate in 


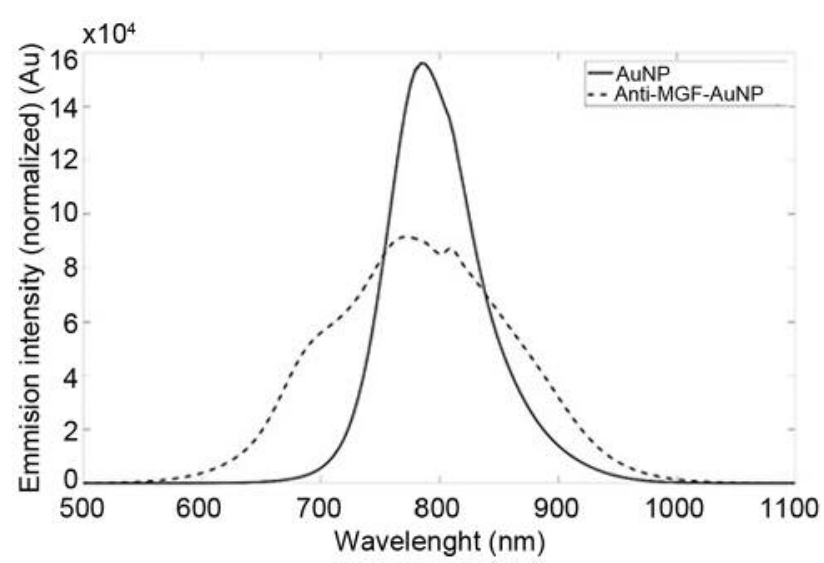

Figure 1. Emission spectra of mercaptosuccinic acid-conjugated gold nanoparticles (AuNPs) alone and conjugated to antibody to mechanogrowth factor (MGF). Peak photoluminescence of AuNPs was $800 \mathrm{~nm}$ excited at $488 \mathrm{~nm}$.

fluorescence, reflection and phase-contrast modes, and it was provided with high transmission objectives with reduced autofluorescence. Fluorescent image acquisition was conducted via LED light source excitation at $620 \mathrm{~nm}$ with emission long-pass filter at $700 \mathrm{~nm}$ with image processing with Olympus cellSens software (KeyMed House). All the near-infrared images acquired are displayed in pseudocolour (red) format.

\section{Results}

Gold nanoparticle characterisation. Optical characterisation of the synthesised unconjugated AuNP, and the anti-MGFAuNP using spectroscopy is demonstrated in Figure 1. TEM of the MSA-AuNPs indicated an average core diameter of 2 $\mathrm{nm}$ as previously reported by our Institution (18).

Dot-blot analysis of conjugated anti-MGF-AuNPs. The findings from our dot-blot experiment is demonstrated in Figure 2. The three dots from left to right were from serial dilutions of the MGF peptide, and the fourth dot was a control peptide. The findings demonstrated decreasing luminescence with decreasing concentration of the MGF peptide, with the absence of luminescence in the control scrambled peptide. This confirmed conjugation of the MGF antibody to the AuNPs and its specificity in binding to the MGF peptide.

Anti-MGF-conjugated AuNPs bind to colon cancer cell lines. On viewing the cells under confocal microscopy, the positive control PC3 cell line demonstrated uniform binding of the anti-MGF-AuNPs (Figure 3A), while the negative control HUVECs did not demonstrate any evidence of binding of anti-MGF-AuNPs (Figure 3B). Both SW620 and HT29 colon cancer cell lines demonstrated uniform fluorescence, confirming binding to anti-MGF-AuNPs, as illustrated in Figure $3 \mathrm{C}$ and $\mathrm{D}$.

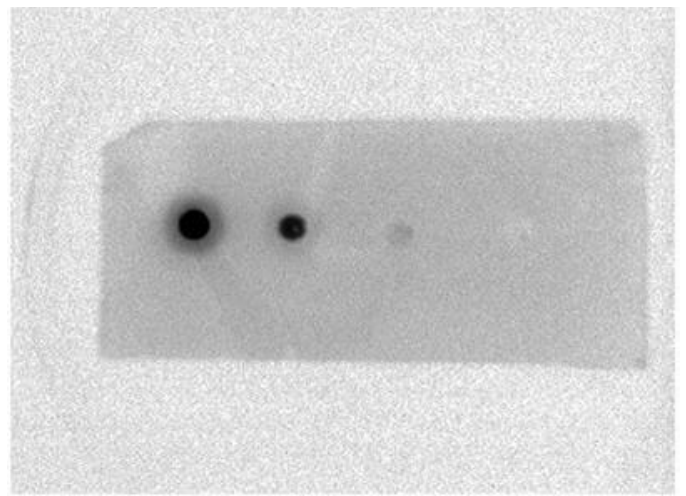

Figure 2. Dot blots representing a decreasing dilution series of mechano-growth factor peptides. The third dot corresponds to the lowest concentration used. The fourth dot represents a control peptide (scrambled sequence).

Anti-MGF-conjugated AuNPs bind to colon cancer tissues. The anti-MGF-conjugated AuNPs were identified to localise to the epithelial cell lining of the positive control prostate cancer tissues (Figure 4A). The normal colon tissues did not demonstrate any evidence of binding to anti-MGFconjugated AuNPs, with no fluorescence identified, as illustrated in Figure 4B. The colon polyp and cancer tissues demonstrated epithelial localisation of anti-MGF-conjugated AuNPs as illustrated in Figure 4C and D.

\section{Discussion}

We successfully designed AuNPs via an aqueous synthesis route by reducing gold salt with DMF and MSA rendering it water-soluble. This was synthesised via a one-pot synthesis route as recently described in the literature by our Institution (16, 18). EDC was used as an acylating agent to form covalent bonds between the MGF antibody and AuNPs. EDC was used to activate the carboxyl group in the MSA and thereafter conjugate to the amine groups on the MGF peptide and MGF antibody. Confirmation of this conjugation process was demonstrated with the use of dot blots. The absorbance spectrum of the anti-MGF-AuNP was 375 to $630 \mathrm{~nm}$ with a fluorescent peak at $800 \mathrm{~nm}$ in the near infra-red region which is important for deep-tissue penetration and is beyond the emission peak of the auto-fluorescence of epithelial tissues, which has been demonstrated to be around $550 \mathrm{~nm}$ (19).

Prostate cancer tissues and the PC3 prostate cancer cell line were used as a positive controls following the work by the Department of Experimental Physiology at the University of Athens for the past few years demonstrating the overexpression of MGF in prostate cancer $(8,17,20,21)$. The anti-MGFAuNPs demonstrated uniform fluorescence in the PC3 cell line, with no fluorescence demonstrated in HUVECs, which we 


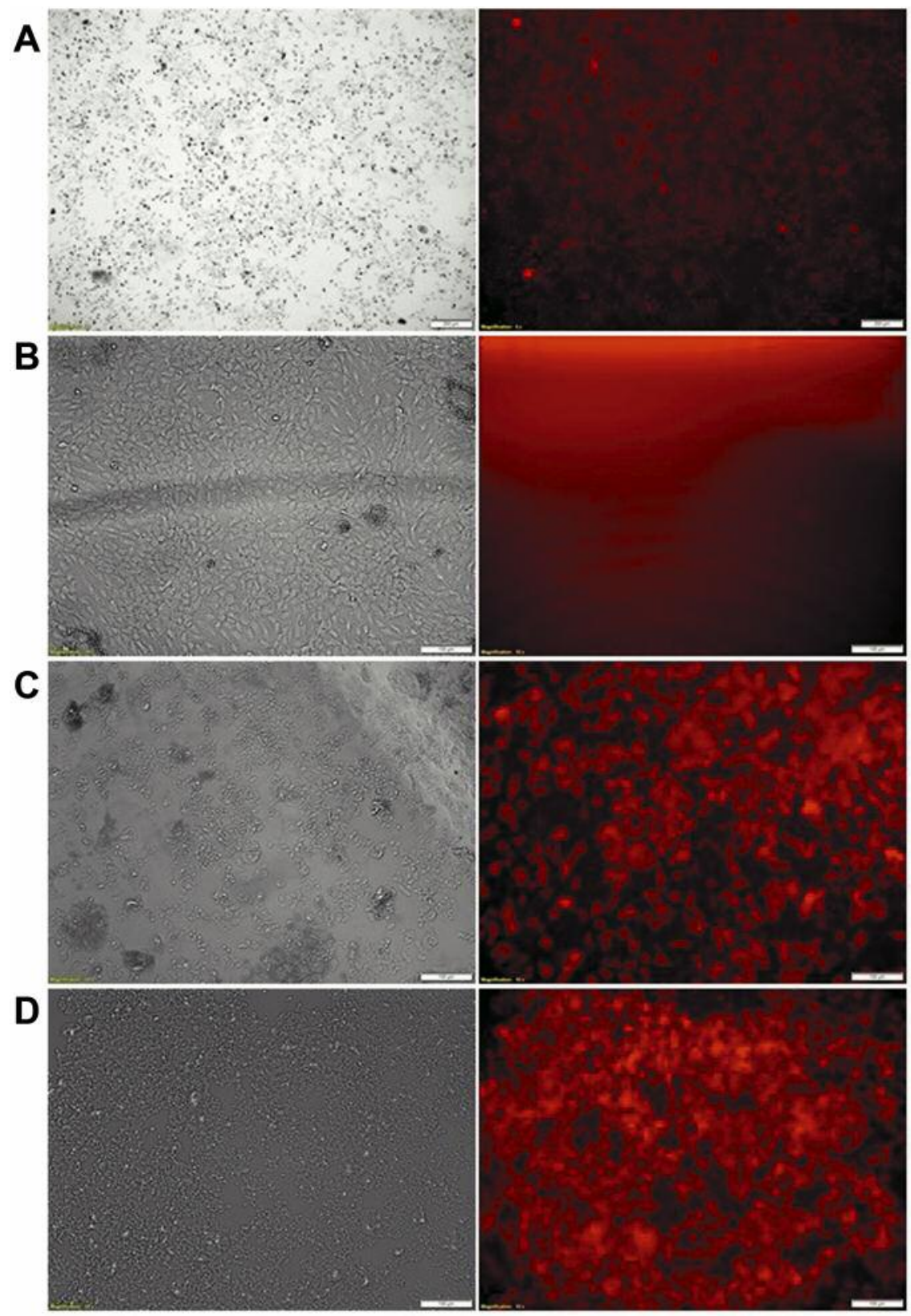

Figure 3. Fluorescent images acquired using confocal microscopy of cells after application of mercaptosuccinic acid-conjugated gold nanoparticles conjugated to antibody to mechano-growth factor. Left column: Differential interference contrast image. Right column: Near infra-red image. A: PC3 cell line (positive control). B: Human umbilical vein endothelial cells (negative control). C: HT29 cell line. D: SW620 cell line. Magnification $\times 4$, bars $=100 \mu \mathrm{m}$.

used as a negative control. We used HUVECs as a negative control since previous studies had identified that endothelial cells, not stimulated by external growth factors, expressed minimal IGF1, including HUVECs $(22,23)$. Following this, we applied anti-MGF-AuNPs to fixed HT29 and SW620 cells, with both cell lines demonstrating good fluorescence following application of the anti-MGF-AuNPs and no fluorescence following application of unconjugated AuNPs.
The anti-MGF-AuNPs bound to prostate cancer tissues in the epithelial lining as illustrated in Figure 4A, while unconjugated AuNPs did not demonstrate any signals. This was similar to the immunohistochemistry images demonstrating MGF expression in prostate cancer tissues by Savvani et al. (8). Colon cancer tissues demonstrated anti-MGF-AuNPs bound to the epithelial layer of tissues, while normal colon tissues did not demonstrate any fluorescence. Colonic polyp 

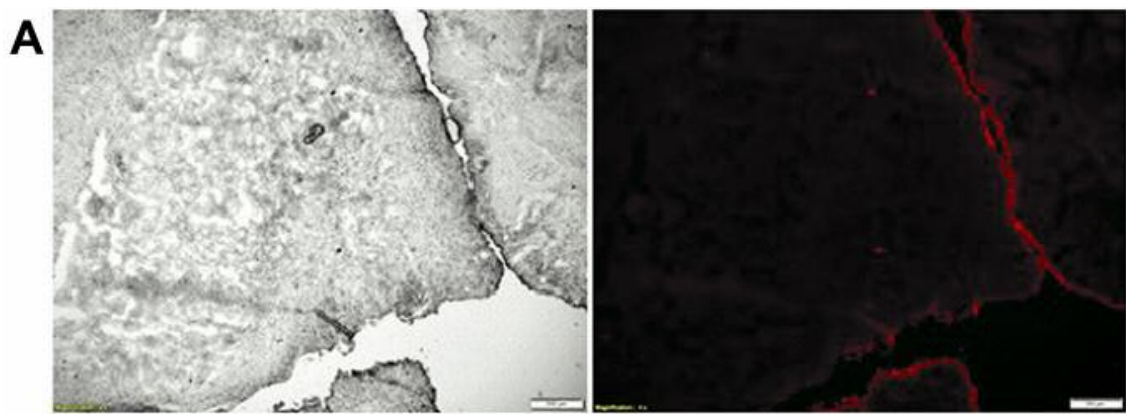

B
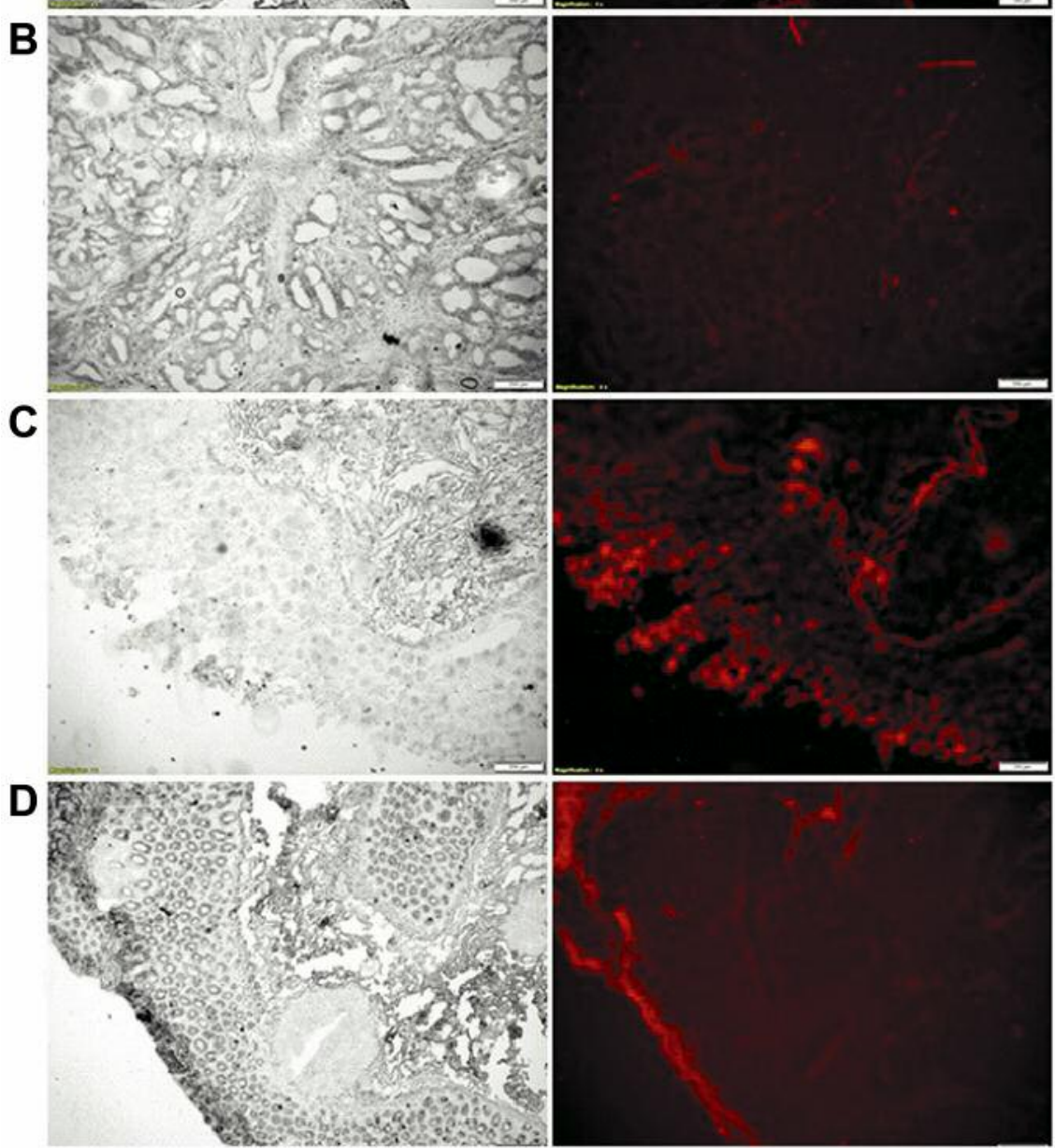

Figure 4. Fluorescent images acquired using confocal microscopy of tissues after application of mercaptosuccinic acid-conjugated gold nanoparticles conjugated to antibody to mechano-growth factor. A: Positive control prostate cancer tissues. B: Normal colonic tissue. C: Colonic polyp. D: Colonic adenocarcinoma. Left column: Differential interference contrast image. Right column: Near infra-red image. Magnification $\times 20$, bars=100 $\mu$ m.

tissues demonstrated similar findings to the colon cancer tissues, with the anti-MGF-AuNPs binding to the epithelial layer of the polyp tissues. Our findings suggest that MGF is expressed by colon cancer and colonic polyps, and not by normal colon tissues. Colonic polyps are known precursor lesions for colon cancer via the adenoma-carcinoma sequence, and the expression of MGF peptide in these lesions indicates that the expression of MGF is an early event in carcinogenesis.
We describe the production of water-soluble functionalised anti-MGF-AuNPs which were used to investigate the expression of MGF peptide in colon cancer. Our findings suggest that MGF peptide is expressed by colon cancer cells, tissues and colonic polyps, and not expressed by normal colon tissues and therefore MGF can be utilized as a potential target for drug-delivery agents. 


\section{Conflicts of Interest}

None to declare.

\section{Authors' Contributions}

Design, data collection: Swethan Alagaratnam, Shi-yu Yang, Bala Ramesh. Analysis and writing the article: Swethan Alagaratnam, Barry Fuller, Marilena Loizidou, Bala Ramesh.

\section{References}

1 Bray F, Ferlay J, Soerjomataram I, Siegel RL, Torre LA, Jemal A. Global cancer statistics 2018: GLOBOCAN estimates of incidence and mortality worldwide for 36 cancers in 185 countries. CA Cancer J Clin 68(6): 394-424, 2018. PMID: 30207593. DOI: $10.3322 /$ caac. 21492

2 Bowel Cancer Survival Statistics. Cancer Res UK (2015). Available from: http://www.cancerresearchuk.org/health-professional/cancerstatistics/statistics-by-cancer-type/bowel-cancer/survival.

3 Matheny RW, Nindl BC and Adamo ML: Minireview: Mechanogrowth factor: a putative product of IGF-I gene expression involved in tissue repair and regeneration. Endocrinology 151(3): 865-875, 2010. PMID: 20130113. DOI: 10.1210/ en.2009-1217

4 Zanou N and Gailly P: Skeletal muscle hypertrophy and regeneration: interplay between the myogenic regulatory factors (MRFs) and insulin-like growth factors (IGFs) pathways. Cell Mol Life Sci CMLS 70(21): 4117-4130, 2013. PMID: 23552962. DOI: $10.1008 / \mathrm{s} 00018-013-1330-4$

5 Dluzniewska J, Sarnowska A, Beresewicz M, Johnson I, Srai SK, Ramesh B, Goldspink G, Górecki DC and Zoblocka B: A strong neuroprotective effect of the autonomous C-terminal peptide of IGF1 Ec (MGF) in brain ischemia. FASEB J Off Publ Fed Am Soc Exp Biol 19(13): 1896-1898, 2005. PMID: 16144956. DOI: 10.1096/fj.05-3786fje

6 Luo Z, Jiang L, Xu Y, Li H, Xu W, Wu S, Wang Y, Tang Z, Lv $\mathrm{Y}$ and Yang L: Mechano-growth factor (MGF) and transforming growth factor (TGF)- $\beta 3$ functionalized silk scaffolds enhance articular hyaline cartilage regeneration in rabbit model. Biomaterials 52: 463-475, 2015. PMID: 25818452. DOI: 10.1016/j.biomaterials.2015.01.001

7 Stavropoulou A, Halapas A, Sourla A, Philippou A, Papageorgiou E, Papalois A and Koutsilieris M: IGF1 Expression in infarcted myocardium and MGF E peptide actions in rat cardiomyocytes in vitro. Mol Med 15(5-6): 127-135, 2009. PMID: 19295919. DOI: 10.2119/molmed.2009.00012

8 Savvani A, Petraki C, Msaouel P, Diamanti E, Xoxakos I and Koutsilieris M: IGF-IEc expression is associated with advanced clinical and pathological stage of prostate cancer. Anticancer Res 33(6): 2441-2445, 2013. PMID: 23749893.

9 Alexandraki KI, Philippou A, Boutzios G, Theohari I, Koutsilieris M, Delladetsima IK and Kaltsas GA: IGF-IEc expression is increased in secondary compared to primary foci in neuroendocrine neoplasms. Oncotarget 8(45): 79003-79011, 2017. PMID: 29108282. DOI: 10.18632/oncotarget.20743

10 Philippou A, Armakolas A, Panteleakou Z, Pissimissis N, Nezos A, Theos A, Kaparelou, Armakolas N, Pneumaticos SG and Koutsilieris M: IGF1Ec expression in MG-63 human osteoblastlike osteosarcoma cells. Anticancer Res 31(12): 4259-4265, 2011. PMID: 22199289.
11 Shang J, Hang J, Fan X and Liu H: The role of mechano-growth factor E peptide in the regulation of osteosarcoma. Oncol Lett 10(2): 697-704, 2015. PMID: 26622556. DOI: 10.3892/ ol.2015.3339

$12 \mathrm{Xu} \mathrm{J}$ and Shang L: Emerging applications of near-infrared fluorescent metal nanoclusters for biological imaging. Chin Chem Lett 29(10): 1436-1444, 2018. DOI: 10.1016/ j.cclet.2017.12.020

13 Qu X, Wang J, Zhang Z, Koop N, Rahmanzadeh R and Hüttmann G: Imaging of cancer cells by multiphoton microscopy using gold nanoparticles and fluorescent dyes. J Biomed Opt 13(3): 031217, 2008. PMID: 18601541. DOI: 10.1117/1.2942373

14 von Maltzahn G, Park J-H, Agrawal A, Bandaru NK, Das SK, Sailor MJ and Bhatia SN: Computationally guided photothermal tumor therapy using long-circulating gold nanorod antennas. Cancer Res 69(9): 3892-3900, 2009. PMID: 19366797. DOI: 10.1158/0008-5472.CAN-08-4242

15 Kopwitthaya A, Yong K-T, Hu R, Roy I, Ding H, Vathy LA, Bergey EJ and Prasad PN: Biocompatible PEGylated gold nanorods as colored contrast agents for targeted in vivo cancer applications. Nanotechnology 21(31): 315101, 2010. PMID: 20622303. DOI: $10.1088 / 0957-4484 / 21 / 31 / 315101$

16 Ramesh BS, Giorgakis E, Lopez-Davila V, Dashtarzheneha AK and Loizidou M: Detection of cell surface calreticulin as a potential cancer biomarker using near-infrared emitting gold nanoclusters. Nanotechnology 27(28): 285101, 2016. PMID: 27255548. DOI: $10.1088 / 0957-4484 / 27 / 28 / 285101$

17 Armakolas A, Philippou A, Panteleakou Z, Nezos A, Sourla A, Petraki $\mathrm{C}$ and Koutsilieris M: Preferential expression of IGF1Ec (MGF) transcript in cancerous tissues of human prostate: evidence for a novel and autonomous growth factor activity of MGF E peptide in human prostate cancer cells. Prostate 70(11): 1233-1242, 2010. PMID: 20564425. DOI: 10.1002/pros.21158

18 Giorgakis E, Ramesh B, Kamali-Dashtarzheneh A, Fusai GK, Imber C, Tsironis D and Loizidou M: Demonstration of calreticulin expression in hamster pancreatic adenocarcinoma with the use of fluorescent gold quantum dots. Anticancer Res 36(3): 861-867, 2016. PMID: 26976972.

$19 \mathrm{Wu}$ Y and Qu JY: Autofluorescence spectroscopy of epithelial tissues. J Biomed Opt 11(5): 054023, 2006. PMID: 17092172. DOI: $10.1117 / 1.2362741$

20 Armakolas A, Kaparelou M, Dimakakos A, Papageorgious E, Armakolas N, Antonopoulos A, Petraki C, Lekarakou M, Lelovas P, Stathaki M, Psarros C, Donta I, Galanos PS, Msaouel P, Gorgoulis VG and Koutsilieris M: Oncogenic role of the Ec peptide of the IGF1Ec isoform in prostate cancer. Mol Med 21(1): 167-179, 2015. PMID: 25569803. DOI: 10.2119/ molmed.2014.00222

21 Philippou A, Armakolas A and Koutsilieris M: Evidence for the possible biological significance of the IGF1 gene alternative splicing in prostate cancer. Front Endocrinol 4: 31, 2013. PMID: 23519101. DOI: 10.3389/fendo.2013.00031

22 Hansson HA, Jennische E and Skottner A: Regenerating endothelial cells express insulin-like growth factor-I immunoreactivity after arterial injury. Cell Tissue Res 250(3): 499-505, 1987. PMID: 3690631.

23 Glazebrook H, Hatch T and Brindle NPJ: Regulation of insulinlike growth factor- 1 expression in vascular endothelial cells by the inflammatory cytokine interleukin-1. J Vasc Res 35(3): 143149, 1998. PMID: 9647327. DOI: 10.1159/000025577

Received February 25, 2019

Revised March 16, 2019

Accepted March 20, 2019 